\title{
MORFOLOGIA E DISTRIBUIÇÃO SEDIMENTAR EM UM SISTEMA ESTUARINO TROPICAL: BAÍA DE VITÓRIA, ES
}

\author{
Paulo Veronez Júnior, Alex Cardoso Bastos e Valéria da Silva Quaresma \\ Recebido em 23 dezembro, 2008 / Aceito em 18 novembro, 2009 \\ Received on December 23, 2008 / Accepted on November 18, 2009
}

\begin{abstract}
Vitória Bay is an estuarine system along the eastern Brazilian coast that presents great economic importance and unique characteristics. The present study focused on describing the morphology, sedimentary distribution and sonographic patterns along the bay in order to recognize the prevailing sedimentary processes acting along the estuary. An integrated analysis allowed the recognition of four regions associated with distinct processes: the upper estuary is dominated by fluvial input and estuarine processes; a large portion of the central region of the system showed erosive characteristics and morphological adaptations related to the increase in currents caused by the man-induced narrowing of the bay, providing the formation of bedforms; the navigation channel, which shows high rates of sedimentation and is clearly modified by dredging and the estuarine mouth which is dominated by marine processes.
\end{abstract}

Keywords: bathymetry, sidescan sonar, sedimentology, estuary.

RESUMO. A Baía de Vitória é um sistema estuarino da costa leste do Brasil que apresenta grande importância econômica e características ímpares, já que se desenvolveu entre três unidades geomorfológicas distintas. Apesar disto, este ambiente apresenta poucos estudos relacionados às suas características geológicas e oceanográficas. 0 presente trabalho se focou no preenchimento desta lacuna através da descrição da morfologia, da distribuição sedimentar e dos padrões sonográficos da Baía de Vitória, buscando relações entre os mesmos e inferindo os processos sedimentares dominantes em cada trecho do estuário. A análise integrada mostrou boa correlação entre os métodos e revelou a grande complexidade deste sistema estuarino. Três diferentes regiões foram identificadas mostrando processos distintos: o estuário superior apresentou input sedimentar fluvial e processos estuarinos; um largo trecho da região central do sistema apresentou características erosivas, relacionadas a adaptações morfológicas e ao aumento das correntes provocadas pelos estreitamentos artificiais da baía, propiciando a formação de formas de fundo; $\mathrm{e}$ a boca do estuário se apresentou dominada por processos marinhos. Parte da região central do estuário mostrou características mascaradas pela atividade antrópica através da instalação de pontes, aterros e dragagens.

Palavras-chave: ecossondagem, sonar de varredura lateral, sedimentologia, estuário. 


\section{INTRODUÇÃo}

Estuários são ambientes de transição entre os ambientes fluviais e marinhos, onde um ou mais rios encontram 0 mar, e as forçantes de ambos ambientes atuam controlando a dinâmica e a distribuição das propriedades químicas, biológicas e sedimentares (Perillo, 1996). São feições efêmeras do ponto de vista geológico, pois são áreas de deposição sedimentar, e sua morfologia, no geral, reflete às características das principais forçantes que nele atuam.

Cerca de $60 \%$ de todas as grandes cidades se desenvolveram ao redor de estuários (Miranda et al., 2002). Este fato é devido às características abrigadas destes ambientes, que favorecem a navegação e instalação de portos, além de serem as vias de acesso para a navegação nas bacias hidrográficas. Apesar desta ocupação, a interação dos processos físicos, químicos, biológicos e geológicos que regem a renovação e depuração destes ambientes ainda não é bem compreendida (Miranda et al., 2002).

Todos estes fatos contribuem para que a ação antrópica através da introdução de substâncias e/ou de energia atinja níveis de concentração por vezes alarmantes, causando assim efeitos negativos à biota, a saúde e as atividades humanas como navegação, pesca, aqüicultura e recreação. Neste aspecto, a fração lamosa dos sedimentos tem comportamento quase sempre associado a substâncias que se agregam aos mesmos, como matéria orgânica, metais pesados e outros contaminantes provenientes de esgoto doméstico, industrial, atividades agrícolas e navais.

Estudos que visam identificar a morfologia e a distribuição sedimentar dos estuários são importantes para identificação de possíveis zonas de acúmulo de poluentes e sedimentos, além de contribuir para o conhecimento dos sistemas estuarinos e do seu comportamento quanto à distribuição das características sedimentares e físicas. Para tanto, a caracterização morfológica, sedimentar, e 0 imageamento de fundo são ferramentas imprescindíveis que já vem sendo aplicadas com sucesso no estudo dos ambientes marinhos e costeiros em geral (Folk \& Ward, 1957; Ayres Neto, 2000; Quaresma et al., 2000; Carmo, 2006; Bastos et al., 2007; Paolo \& Mahiques, 2008).

Neste contexto, a Baía de Vitória é parte de um complexo sistema costeiro que se tornou rota de transporte e comércio da região após a transferência da capital de Vila Velha para a Ilha de Vitória, para evitar os constantes ataques indígenas, e mantém este posto até hoje, sustentando um importante complexo portuário de vital importância para a economia do estado do Espírito Santo (Lima Jr et al., 1994). Nas últimas décadas, a Baía de Vitória vem sofrendo forte degradação ambiental devido ao extenso processo de urbanização através da ocupação descontrolada de seu entorno, muitas vezes associada a aterros, intensa atividade portuária e, principalmente, devido ao lançamento de esgotos, caracterizando-a como um ambiente eutrófico (Jesus et al., 2004). Contudo, este ambiente apresenta poucos trabalhos publicados em relação às suas características geomorfológicas e sedimentológicas.

0 objetivo deste estudo foi identificar e analisar a distribuição sedimentar e sua relação com a morfologia e formas de fundo da Baía de Vitória, inferindo processos, descrevendo parte deste sistema costeiro e preenchendo esta lacuna do conhecimento.

\section{ÁREA DE ESTUDO}

A Baía de Vitória é a parte principal de um complexo sistema estuarino tropical localizado no estado do Espírito Santo (Fig. 1). 0 sistema apresenta dois canais de comunicação com o mar: 0 Canal da Passagem e o Canal do Porto, que na verdade é a porção Sul da Baía de Vitória. Este sistema é formado pelo deságue de vários rios, sendo o Rio Santa Maria da Vitória (RSMV) de porte médio, e os rios Formate-Marinho, Bubu, Aribiri, Córrego Piranema e o Canal da Costa de pequeno porte.

0 Rio Santa Maria da Vitória é 0 sistema fluvial que contribui com maior volume de água doce para a Baía de Vitória, com vazão média de $15,7 \mathrm{~m}^{3} / \mathrm{s}$, sendo que os demais contribuem com menos de $3 \mathrm{~m}^{3} / \mathrm{s}$ (Rigo, 2004). Segundo Rigo (2004), uma característica importante deste rio é a presença de duas barragens em seu médio curso: a de Rio Bonito, de regulação anual; e a de Cachoeira Suíça, de regulação diária, além da barragem de regularização de nível da Companhia Espírito-Santense de Saneamento (CESAN), presente em seu baixo curso.

0 sistema estuarino em questão apresenta três unidades geomorfológicas distintas formando seus contornos: as Colinas e Maciços Costeiros, compostos por maciços rochosos de origem ígnea que formam 0 arquipélago de Vitória, dominando a parte centro sul deste sistema costeiro; os Tabuleiros Costeiros, formados pela Formação Barreiras e ocupando a região ao Norte do sistema; e as Planícies Costeiras, formadas por sedimentos quaternários provenientes das unidades anteriores e do aporte fluvial, ocupando a região principalmente nas praias, planícies fluviomarinhas e regiões de manguezal (Projeto RADAMBRASIL, 1983).

0 trecho estudado do sistema estuarino tem a sua dinâmica dominada principalmente pelas marés, sendo estas classificadas como micromarés $(\mathrm{H}<2 \mathrm{~m})$ semidiurnas, com pequenas desigualdades diurnas (Chacaltana et al., 2003; Rigo, 2004). Chacaltana et al. (2003) e Rigo (2004) também observaram que as áreas de manguezal na Baía de Vitória são responsáveis por um 


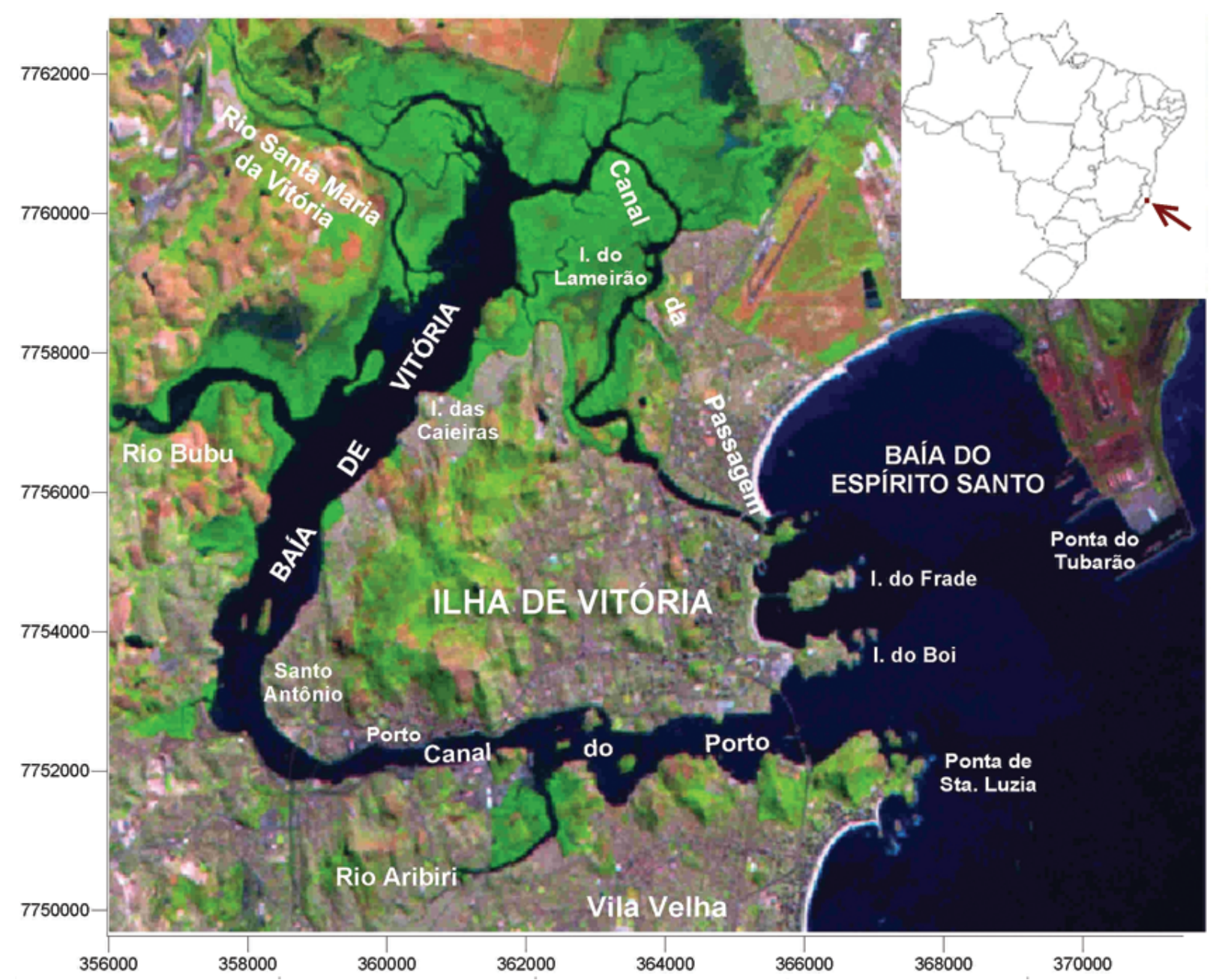

Figura 1 - Localização do sistema costeiro. Imagem do satélite Landsat 7 em composição falsa-cor (R-5; G-4; B-3) dos sensores ETM+, elaborada no software SPRING 5.02 (Camara et al., 1996) em UTM datum WGS-84. 0 trecho estudado corresponde à Baía de Vitória e ao Canal do Porto.

acréscimo das velocidades das correntes na baía. As mudanças no contorno da Baía de Vitória proporcionaram o surgimento de estreitamentos artificiais da baía que tem conseqüências nas correntes e no comportamento da maré ao longo do estuário.

Devido à presença de dois canais de comunicação da Baía de Vitória com o mar, existe na região do extremo norte da baía e do Canal da Passagem uma convergência barotrópica (Sarmento, 1993), resultante do encontro das frentes de maré que se propagam pelos diferentes canais. Esta convergência foi denominada de "tombo" da maré, e caracterizada, inicialmente, por Sarmento (1993), e posteriormente por Maciel et al. (2003) e por Rigo (2004).

As correntes existentes na Baía de Vitória são conseqüências da soma dos efeitos da maré, da vazão dos rios, da morfologia, da estratificação, das ondas e dos ventos, já que a baía apresenta um largo trecho orientado no sentido dos ventos predominantes (NE e SW). 0 fluxo de maré vazante é dominante durante as sizígias, perdendo força quando se aproxima da quadratura (Rigo, 2004).

Poucos são os trabalhos acerca da morfologia, circulação e distribuição de sedimentos na Baía de Vitória, sendo a maioria informações disponíveis em cartas náuticas, relatórios de licenciamento ambiental e monografias não publicadas na forma de artigo científico. Dentre estes trabalhos, merecem destaque os realizados por Sarmento (1993); Chacaltana et al. (2003); Rigo (2004); Nunes (2005); D'Agostini (2005); e Bastos et al. (2007).

D'Agostini (2005) realizou um trabalho de classificação faciológica dos sedimentos da Baía de Vitória e do Canal da Passagem. A autora observou que os sedimentos superficiais das regiões denominadas de "Fundo da Báa" e Canal do Porto, nem sempre correspondem diretamente com a hidrodinâmica, e 
sugere os aportes fluviais como a provável fonte dos sedimentos lamosos. Além disso, a grande quantidade de matéria orgânica encontrada indica uma eutrofização da Baía de Vitória devido à elevada urbanização, que aporta a baía com despejo de esgotos domésticos e lixo.

\section{METODOLOGIA}

Para o estudo morfológico e sedimentológico da Baía de Vitória foram utilizados dados batimétricos compilados de várias fontes reduzidos ao nível de maré utilizado pela DHN, amostras sedimentares coletadas na região através de busca-fundo do tipo VanVeen, e imageamento do fundo da Baía de Vitória obtido através de sonografia. Todos os dados estão posicionados em UTM (WGS84), e foram utilizados para a elaboração de mapas (por krigagem e por interpretação direta), onde se identificaram as variações morfológicas e a variação das características sedimentares (ambos por interpolação de dados) e acústicas do fundo (através de interpretação manual), buscando as correlações entre as mesmas.

\section{Batimetria}

Os dados utilizados para a confecção do mapa batimétrico foram compilados de várias fontes, tais como cartas náuticas da Marinha do Brasil; levantamentos batimétricos realizados pelo Grupo de Estudo e Ações em Recursos Hídricos (GEARH) através de ecobatímetro monofeixe, e cedidos pelo Dr. Julio T. A. Chacaltana (Laboratório de Simulação de Escoamento com Superfície Livre LABESUL, Departamento de Engenharia Ambiental-UFES); e dados de folhas de bordo cedidos pela Marinha do Brasil (DHN).

\section{Caracterização sedimentar}

A análise da distribuição sedimentar de fundo da Baía de Vitória foi realizada através da coleta de 101 amostras superficiais de fundo. As amostras foram peneiradas a seco de 0,5 em 0,5 phi, sendo que a fração lamosa (silte e argila) foi separada a úmido em peneira de 4 phi. Para a análise estatística das amostras foi utilizado o pacote estatístico GRADISTAT (Blott \& Pye, 2001), que calculou os parâmetros estatísticos segundo a metodologia proposta por Folk \& Ward (1957). Além destas análises foi feita queima para obtenção do percentual de carbonato presente nos sedimentos.

Para uma análise mais criteriosa, os dados estatísticos resultantes da granulometria foram texturalmente separados segundo a classificação de Folk (1954) e presente em Dias (2004). Também foram texturalmente e composicionalmente separados segundo a classificação modificada de Larsonneur (Dias, 1996). A distribuição das amostras utilizadas está exposta na Figura 2.

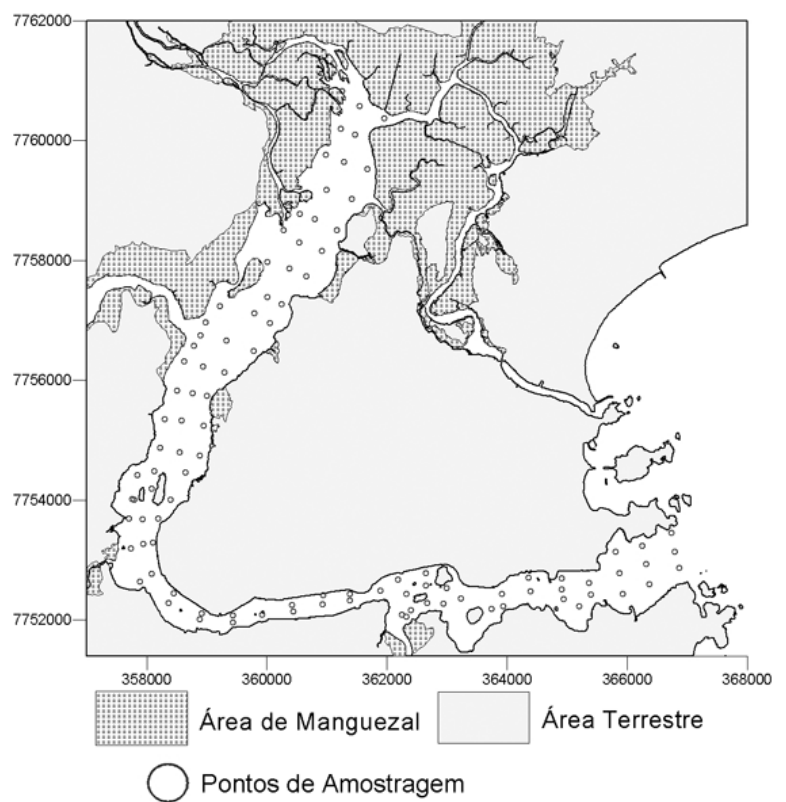

Figura 2 - Localização dos pontos de coleta de sedimentos.

\section{Imageamento do fundo}

0 levantamento de sonar teve 0 objetivo de identificar as principais feições morfológicas de fundo, relacionando com sua textura granulométrica correspondente, visando o entendimento dos padrões de distribuição destes pela baía.

Para isto, foram coletados aproximadamente $25 \mathrm{~km}$ de linhas sonográficas sendo que a navegação foi realizada pelo canal principal da baía desde a sua desembocadura até 0 seu limite interior, visando cobrir toda a extensão longitudinal do estuário.

0 imageamento do fundo da Baía de Vitória foi obtido utilizando-se um sonar de varredura lateral Modelo Edgetech 4100 com towfish 272TD, operando com uma freqüência de $500 \mathrm{kHz}$ e varredura variando de 100 a $50 \mathrm{~m}$. Todos os dados sonográficos foram obtidos digitalmente e já integrados com posicionamento por GPS. Estes dados foram processados e interpretados usando o programa SonarWizMAP-4 da Chesapeake Technology. Os padrões sonográficos foram classificados segundo a intensidade, a rugosidade e a forma de fundo apresentada pelos registros, sempre nomeando de acordo com a composição ou forma de fundo correspondente.

\section{RESULTADOS}

\section{Descrição morfológica}

Como a área do canal de acesso ao Porto de Vitória foi a mais alterada por aterros e dragagens, a morfologia do canal principal não foi interpretada neste trecho (Fig. 3). 

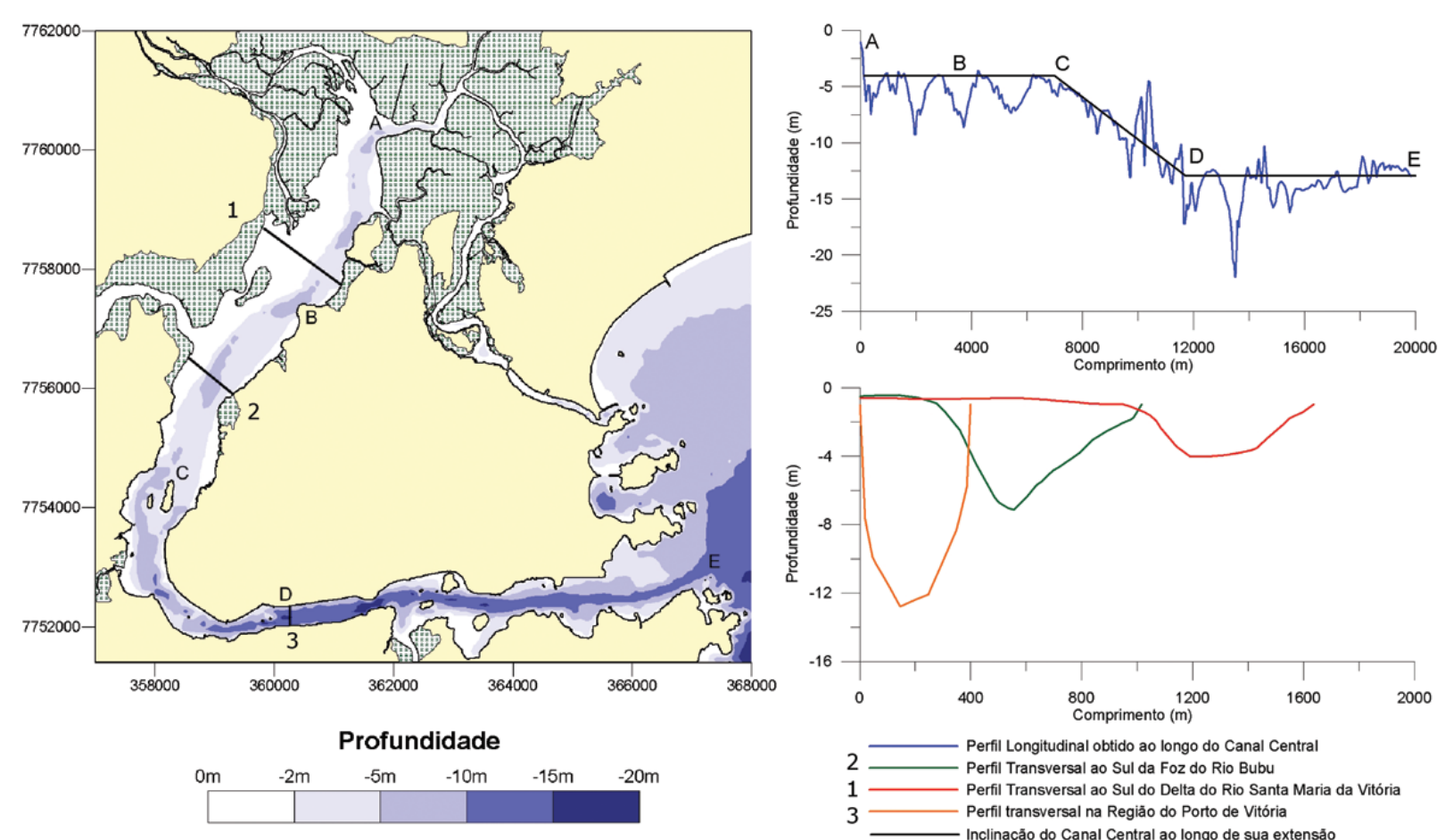

Figura 3 - Mapa batimétrico, perfil longitudinal e perfis transversais da Baía de Vitória. As localizações do perfil longitudinal estão exemplificadas pelas letras correspondentes à esquerda, enquanto a localização das seções transversais é ilustrada pelas linhas transversais. A região localizada entre os pontos D e E, representa a região alterada por dragagens de retificação do canal central do estuário.

Os contornos da Baía de Vitória são bastante recortados devido principalmente à presença constante dos maciços rochosos que formam a llha de Vitória, responsáveis pela grande presença de enseadas, estreitamentos (também associados a aterros) e ilhas neste ambiente, assim como observou Nunes (2005). Estes maciços estão presentes desde a boca deste sistema estuarino, até próximo ao RSMV, onde este tributário apresenta ramificações no encontro de seu canal com a baía, caracterizando o que pode ser descrito como um depósito deltaico.

As vertentes da Baía de Vitória são muito íngremes, contínuas, e tornam a baía estreita, limitando o desenvolvimento de planícies de inundação desde a boca do estuário até as ilhas próximas ao Bairro Santo Antônio. A partir deste ponto, os afloramentos rochosos que formam a llha de Vitória permitem 0 alargamento da baía e diminuem de freqüência em direção ao delta, onde a planície costeira compõe a maior parte dos contornos da baía e permite 0 desenvolvimento de extensos manguezais ao norte da Ilha de Vitória. A influência do Grupo Barreiras se restringe apenas a um pequeno trecho ao norte da planície de inundação do sistema estuarino.

A orientação NE-SW da baía, característica de toda a porção Noroeste, é substituída pela orientação E-W na região próxima a
Santo Antônio, formando a inflexão da Baía de Vitória.

A batimetria da Baía de Vitória se mostra bastante complexa, onde se observa a presença de um canal principal ao longo de toda a baía cercado por grandes áreas planas de baixa profundidade, sendo que este canal encontra-se artificialmente adaptado para navegação na região do canal de acesso ao Porto de Vitória.

0 canal principal é estreito e relativamente raso (até 8 metros de profundidade) na região ao norte da Ilha das Caieiras, com sua Iocalização próxima aos contornos da llha do Lameirão, onde são presentes extensos manguezais que diminuem sua área de cobertura rumo ao sul. Neste trecho fica evidente a morfologia do canal associada a margens bastantes planas que não chegam a $50 \mathrm{~cm}$ de profundidade na maré baixa (perfis 1 e 2 da Fig. 3). Este canal se alarga a partir da Ilha das Caieiras para 0 sul, tomando posição central no estuário e desviando nas regiões com presença de ilhas. No trecho correspondente à inflexão da Baía de Vitória, o canal principal se torna gradualmente mais profundo (até 12 metros de profundidade), e a baía se estreita. Nesta região, os efeitos da morfologia somados aos efeitos das dragagens aumentam em aproximadamente 8 metros a profundidade do canal principal deste trecho até a boca do estuário (Fig. 3). 


\section{Distribuição sedimentar}

Os sedimentos da Baía de Vitória, no geral, são compostos de areia lamosa e lama, com presença de conchas e carapaças de organismos associados às frações mais grossas e/ou cascalhosas. A análise da composição biodetrítica não é objetivo deste trabaIho. Existe um aumento no diâmetro médio dos grãos próximo à Ilha do Boi, ao delta do RSMV e nos estreitamentos existentes nos arredores do bairro Santo Antônio.

No mapa de distribuição textural, segundo a classificação de Folk (1954) descrita em Dias (2004), se verifica grande irregularidade da distribuição sedimentar na área estudada. Há uma presença dominante das texturas lama arenosa e lama, interrompida por três faixas de areia lamosa expressivas: a primeira se encontra na região do delta do RSMV, tendo seu formato associado ao mesmo; a segunda se iniciando ao sul da foz do Rio Bubu, estendendo-se até a região da baía a oeste do Bairro Santo Antônio, e a terceira faixa encontra-se na área ao sul de Santo Antônio, estendendo-se até próximo ao Porto de Vitória (Fig. 4). Existe uma grande área de sedimentos arenosos associada à desembocadura da baía, ao sul da llha do Boi, e também são verificadas pequenas manchas cascalhosas e areno-lamosas associadas a fragmentos de conchas e afloramentos de rochas ao longo de toda a baía, aumentando a complexidade exibida por esta classificação textural. Na área central do Canal do Porto, as manchas arenosas não foram interpretadas devido às dragagens realizadas.

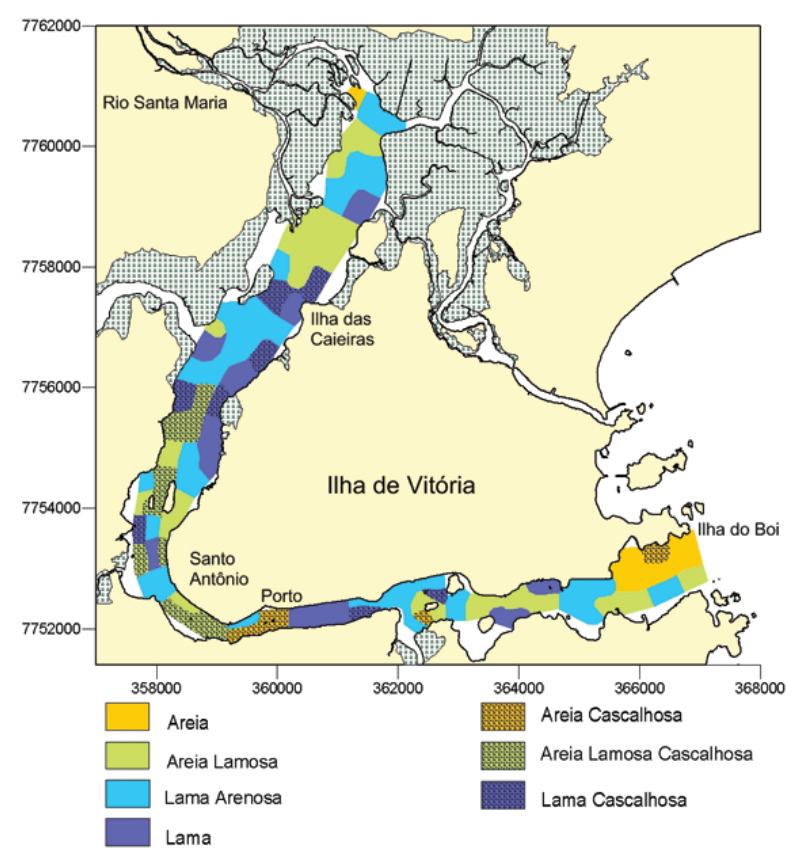

Figura 4 - Mapa de classificação textural dos sedimentos da Baía de Vitória, segundo a classificação de Folk (1954).
Já 0 mapa de classificação composicional e textural segundo a classificação modificada de Larsonneur (Dias, 1996) mostra uma distribuição mais homogênea, onde 0 padrão textural dominante é o lamoso terrígeno. Observa-se a presença de uma grande faixa longitudinal de margas (denominadas em Dias, 1996, referem-se a lamas carbonáticas) na região desde a Ilha das Caieiras até próximo ao Bairro de Santo Antônio, e esta faixa tende a se posicionar ao longo da região central da Baía de Vitória, junto ao canal principal (Fig. 5). Margas são sedimentos lamosos com presença de restos de organismos carbonáticos (moluscos, gastrópodes, entre outros) e/ou de seus fragmentos superior a 30\%. Também foi possível observar a presença de sedimentos arenosos litoclásticos na desembocadura da baía. A presença de fundos arenosos, segundo a classificação de Dias (1996), também pode ser observada em pontos mais restritos, como 0 associado à foz do RSMV, e ao longo da inflexão morfológica da baía, onde ocorrem estreitamentos.

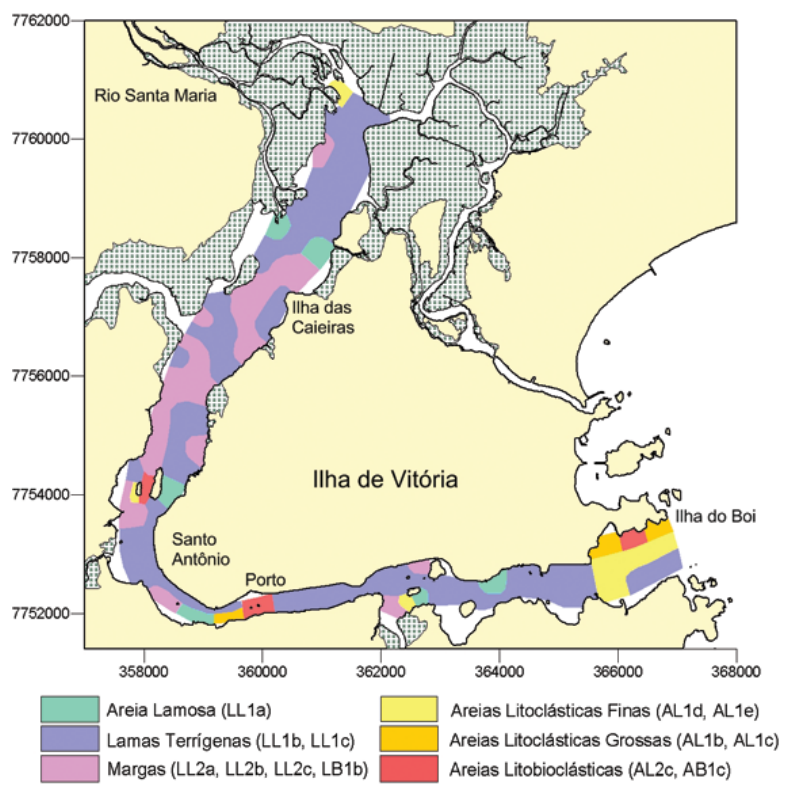

Figura 5 - Mapa de classificação textural dos sedimentos da Baía de Vitória, segundo a classificação modificada de Larsonneur (Dias, 1996).

A distribuição do percentual de lama nos sedimentos foi separada seguindo a classificação modificada de Larsonneur (Dias, 1996), assim como mostra a Figura 6. Este mapa enfatiza a grande concentração de sedimentos coesivos presentes na Baía de Vitória, cuja média é de mais de 50\%. Este padrão dominante é interrompido por três faixas onde o teor de lama é inferior a $50 \%$. Estas áreas correspondem às areias lamosas descritas no mapa baseado na classificação de Folk (1954) (Dias, 2004), e ocorrem na foz do RSMV, do sul da foz do Rio Bubu até junto às ilhas da região de Santo Antônio, e nos estreitamentos artificiais da 
baía onde a mesma sofre a inflexão, próximo ao Porto de Vitória. Junto à desembocadura do estuário, os teores de lama também apresentam valores de menos de $15 \%$, principalmente junto à Ilha do Boi.

\section{Imageamento de fundo}

A análise dos sonogramas permitiu o reconhecimento de 4 tipos distintos de padrões sonográficos: Fundo Homogêneo de Baixa Reflexão, Dunas Subaquosas, Formas de Fundo Irregulares, e Afloramentos Rochosos, assim como ilustra a Figura 7. Também é perceptível 0 grande número de alvos isolados presentes ao longo de toda a baía, compostos principalmente por resquícios de atividades humanas, como naufrágios, cabos, redes, objetos metálicos e resquícios da construção das pontes.

0 padrão Fundo Homogêneo de Baixa Reflexão está relacionado tanto a sedimentos arenosos quanto lamosos, não sendo possível diferenciá-los ao longo de grande parte da baía apenas pelos registros sonográficos. Este padrão homogêneo de baixa reflexão por vezes apresentou marcas de arrasto de redes e marcas de draga, atividades estas que alteram as características sedimentares destas faixas. Por este motivo, estas faixas alteradas são exemplificadas na Figura 8.

Afloramentos Rochosos foram facilmente identificados e se apresentaram importantes em toda a baía, principalmente no trecho entre a inflexão da baía, próximo a Santo Antônio até a desembocadura do estuário. Foram assim nomeados de acordo com o padrão heterogêneo de alta reflexão apresentado pelos mesmos. Os estreitamentos da Baía de Vitória mais expressivos, como era esperado, estão relacionados a este padrão, já que a morfologia da baía é condicionada pelos afloramentos dos granitóides que formam a llha de Vitória e parte do município de Vila Velha (Fig. 9).

0 padrão de Dunas Subaquosas foi assim denominado por causa das formas de fundo regulares apresentadas pelo mesmo. As respectivas feições foram divididas em função de suas dimensões em dunas subaquosas médias (de 0,6 a 5 m de comprimento médio de onda, formato simples, 2D) e dunas subaquosas grandes ou gigantes (entre 10 e $100 \mathrm{~m}$ de comprimento médio de onda, 3D, formato composto, com dunas subaquosas médias sobrepostas e oblíquas) através da classificação descritiva de dunas proposta por Ashley (1990), assim como realizou Bastos et al. (2002) e Paolo \& Mahiques (2008) (Fig. 10). A localização destas dunas é descrita abaixo.

Existe junto ao estreitamento artificial ao sul do bairro Santo Antônio a presença de um campo de dunas subaquosas grandes voltadas para jusante. Estas formas de fundo relacionadas a correntes não são exclusividade desta região, pois há a presença de pequenos campos de dunas subaquosas médias em outros trechos ao norte desta região, assim como foi observado na Figura 7. Tomando o eixo principal do estuário como referência, alguns campos de dunas médias tomam orientação oposta a do campo de dunas grandes, voltando-se para montante. Todas estas formas de fundo regulares estão associadas a fundos de areia ou areias lamosas com baixos teores de lama, e exemplos deste padrão são apresentados na Figura 10.

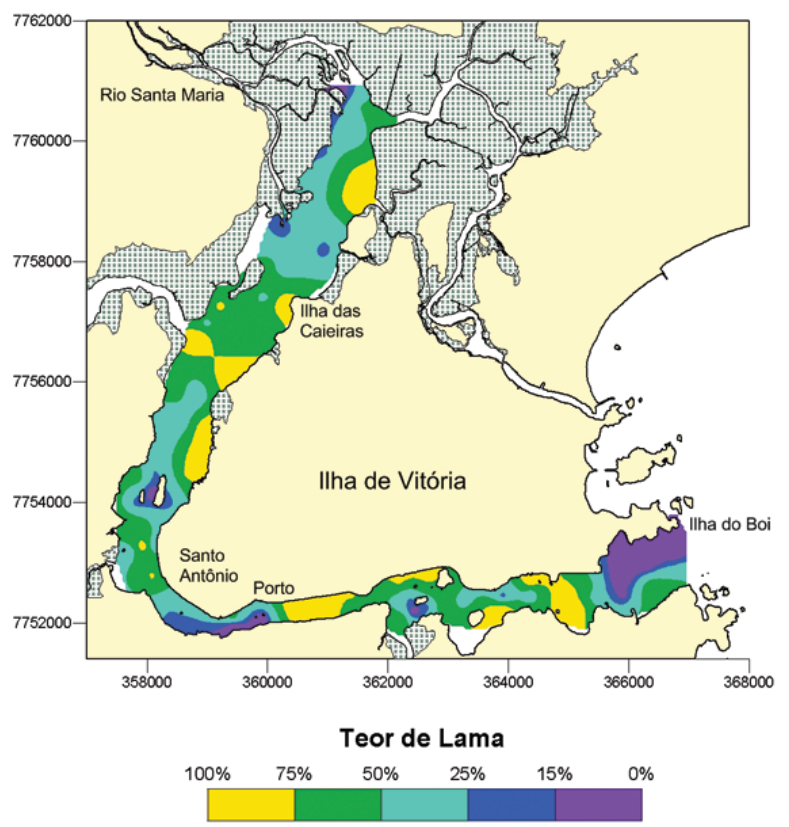

Figura 6 - Mapa de distribuição do percentual de lama nos sedimentos da Baía de Vitória.

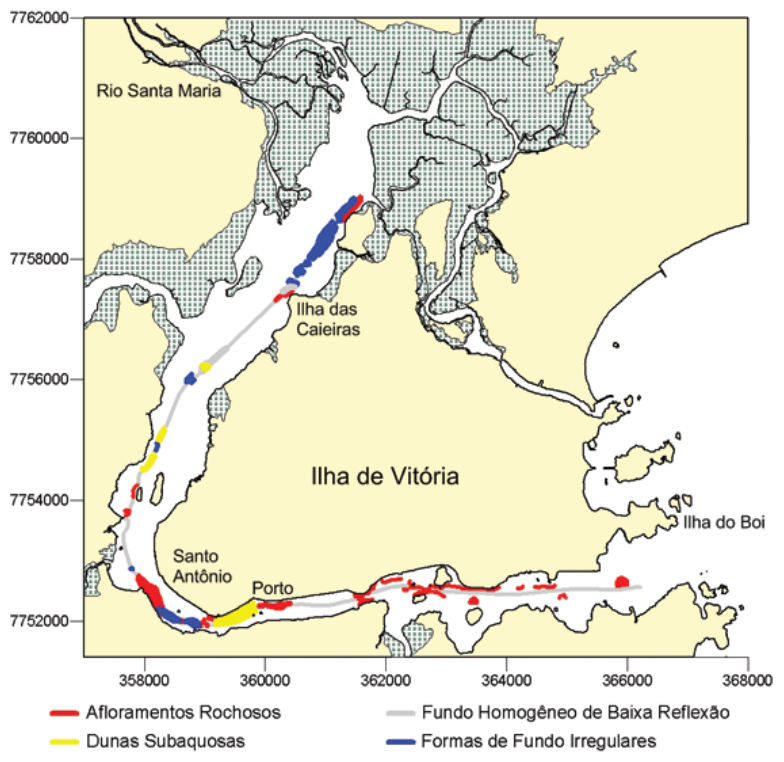

Figura 7 - Distribuição dos padrões sonográficos ao longo da Baía de Vitória. 
(A)

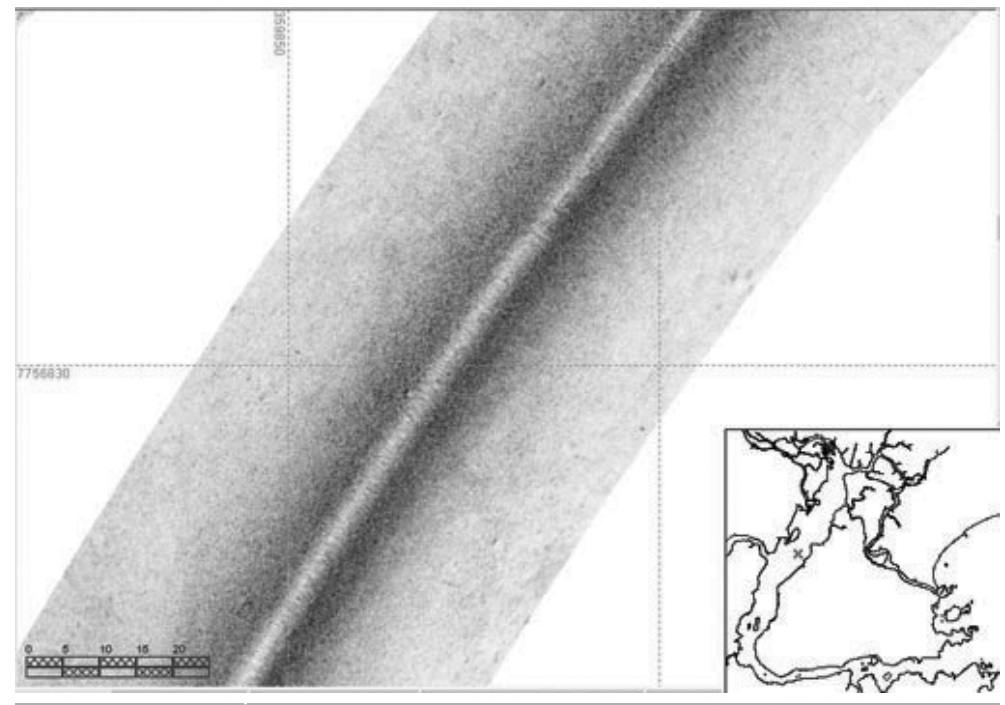

(B)

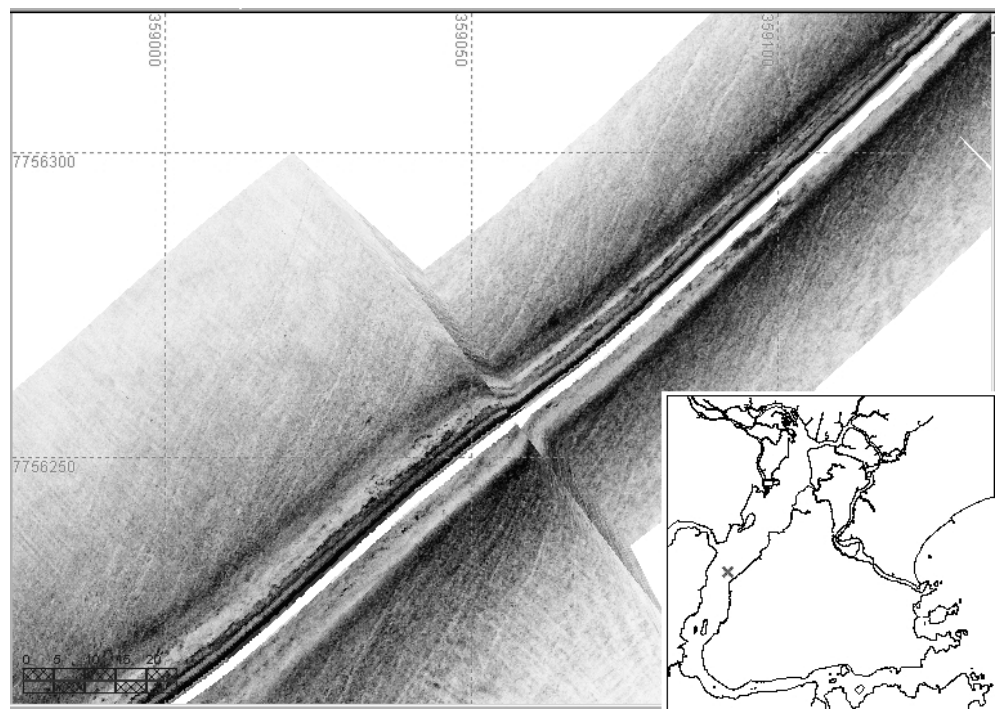

(C)

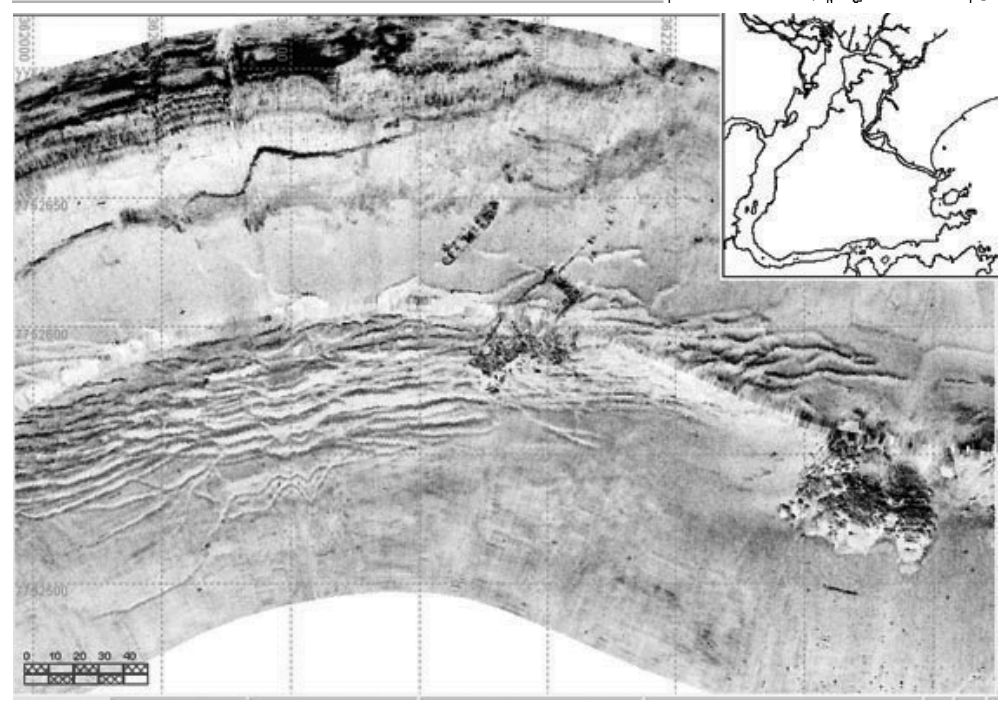

Figura 8 - Exemplos do padrão de Fundo Homogêneo de Baixa Reflexão e de suas alterações antrópicas. Padrão de Fundo Homogêneo de Baixa Reflexão (A); Padrão com marcas de arrasto de redes (B); Padrão com marcas de dragagem e presença de alvos isolados (naufrágios) (C). 
(A)

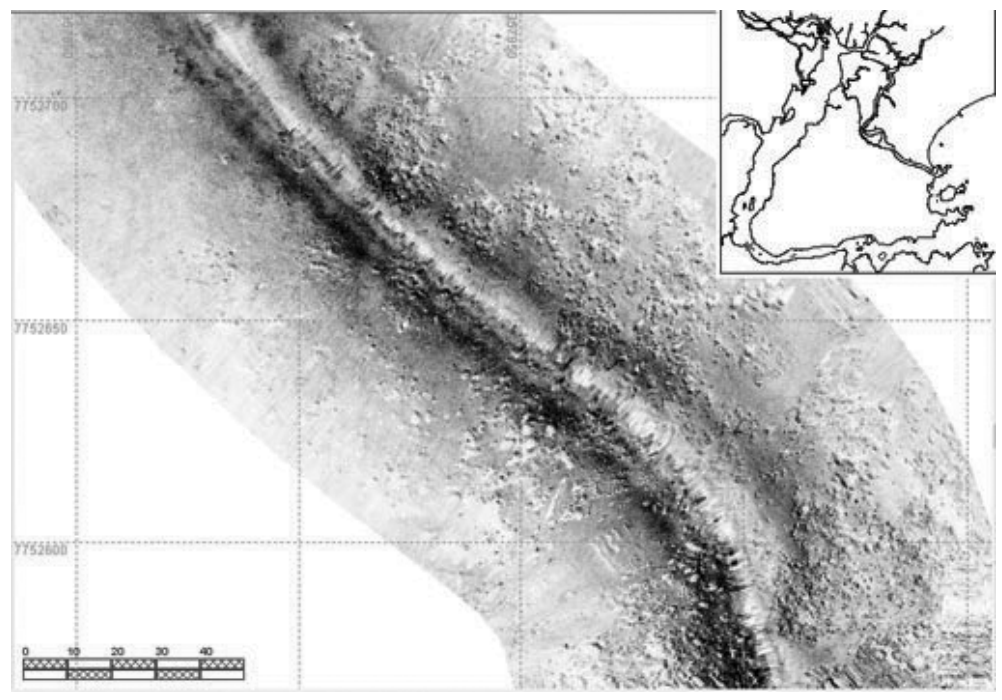

(B)

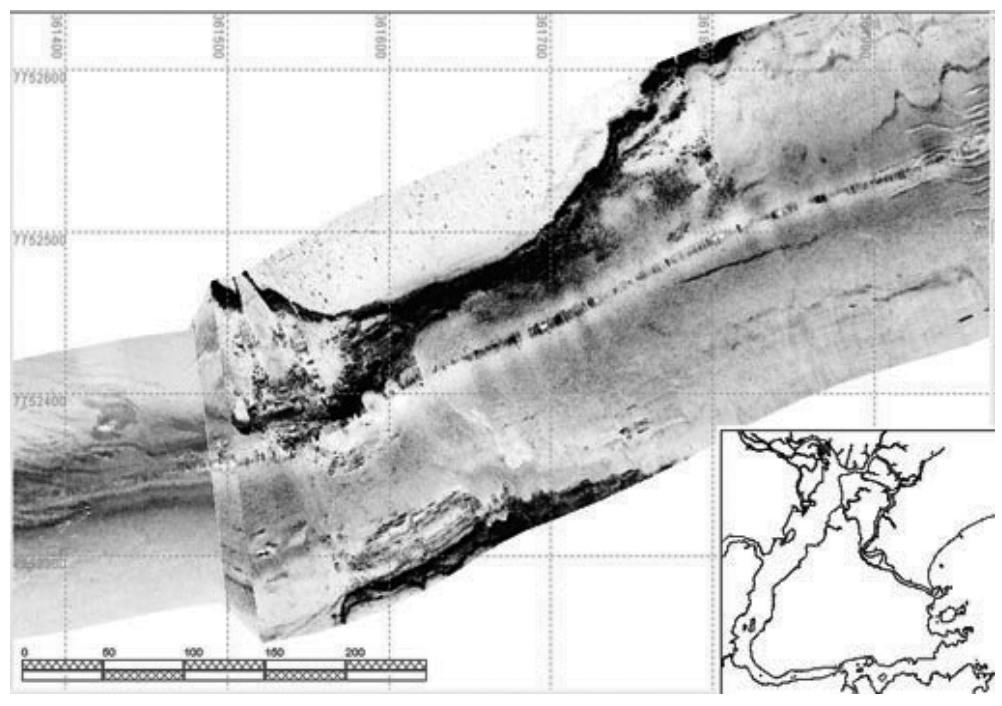

Figura 9 - Padrões relacionados a Afloramentos Rochosos. (A) Registro de sonar associado a blocos de rochas; (B) Registro de sonar associado a afloramentos presentes em um estreitamento natural da baía, na área entre o Penedo e o Forte São João.

0 padrão denominado Formas de Fundo Irregulares é observado em alguns trechos do canal (Fig. 11), mas principalmente, junto à desembocadura do RSMV. Este padrão apresenta uma reflexão heterogênea com formas de fundo irregulares na superfície, que se assemelham a pequenas marcas onduladas. A ocorrência deste padrão é bem nítida no contraste com o padrão de Fundo Homogêneo de Baixa Reflexão dominante no estuário. Em outros trechos a ocorrência deste padrão não apresenta contatos nítidos, observando-se então uma mudança suave entre 0 padrão homogêneo e as Formas de Fundo Irregulares. Além disto, as Formas de Fundo Irregulares nestes trechos tendem a ser menos distinguíveis e de transição suave, assim como ilustra a Figura 11.

\section{DISCUSSÃO}

A análise integrada da morfologia com a distribuição sedimentar e os padrões sonográficos apresentou boa correlação e revelou a grande complexidade dos padrões de sedimentação na baía. Esta complexidade pode ser função da não relação entre a dinâmica atual e a distribuição sedimentar, assim como observou D'Agostini (2005). Bastos et al. (2007) mostram, através de levantamentos sísmicos de alta resolução, que o canal principal da baía na região ao norte do bairro Santo Antônio é fruto de processo erosivo, indicando ainda uma tendência de baixa sedimentação (Fig. 12). A seção sísmica indica que, localmente, 0 aporte de sedimentos finos pode estar recobrindo parcialmente sedimentos pretéritos que foram erodidos na formação do canal. 
(A)

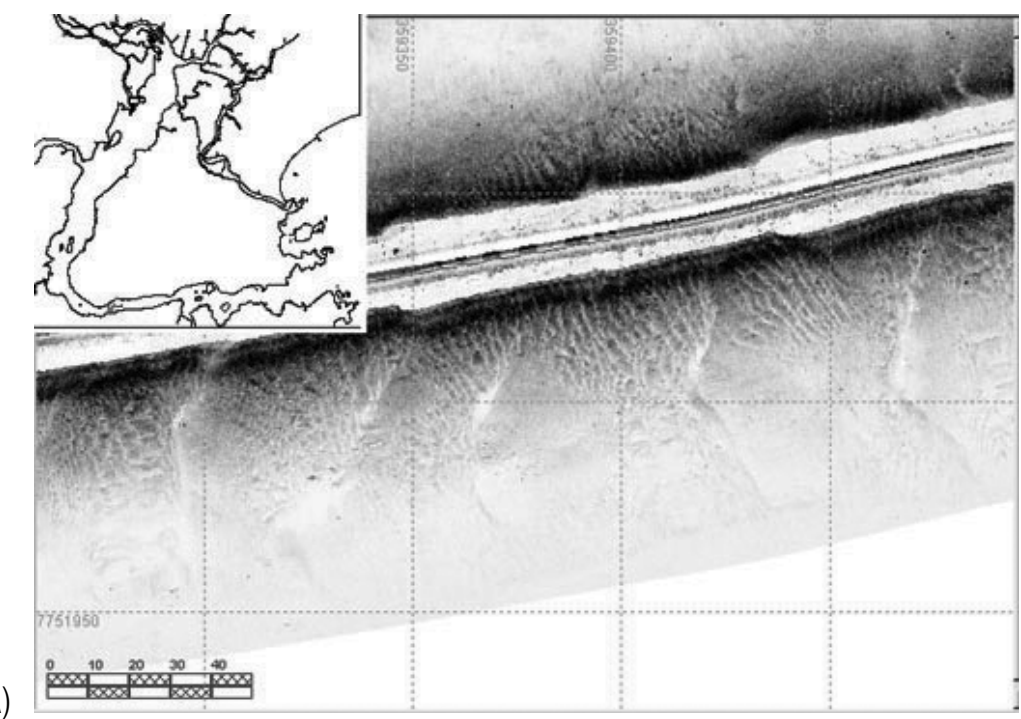

(B)

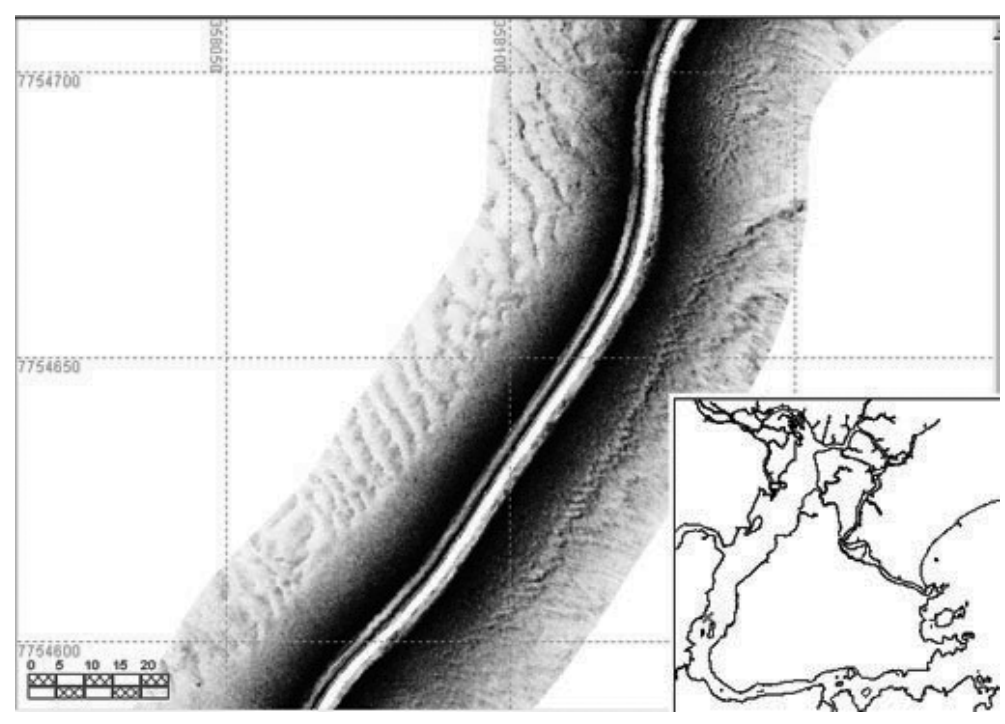

Figura 10 - Exemplos de Dunas Subaquosas encontradas na região. (A) Dunas Subaquosas grandes sobrepostas por dunas médias; (B) Dunas Subaquosas médias em orientação contrária a das dunas grandes, tomando 0 eixo principal do estuário como base.

No geral, a distribuição da fração lamosa no estuário está fragmentada devido a vários possíveis fatores, tais como aumento na intensidade das correntes em função da morfologia do entorno da baía e da ocorrência de sedimentos biogênicos. Estas características da baía separam uma esperada distribuição contínua de altos teores de lama na região central do estuário, em faixas lamosas e areno-lamosas com formas de fundo associadas.

Seguindo uma ordem geográfica (montante-jusante), o canal central da baía se posiciona na margem contrária ao do delta do RSMV, junto à Illha do Lameirão. Este posicionamento tem relação com a deposição dos sedimentos provenientes do rio na direção desta ilha através do delta, que pode ter provocado um deslocamento do canal principal da baía ao longo do tempo geológico. Esta característica é evidenciada simplesmente pela existência do delta do RSMV, que enfatiza o domínio dos processos fluviais neste trecho do sistema estuarino.

A distribuição textural dos sedimentos exposta nos mapas de classificação de acordo com Folk (1954), e de teor de lama, mostram três faixas areno-lamosas na Baía de Vitória, estando associadas ao aparecimento das formas de fundo tipo dunas subaquosas e as chamadas de irregulares. A faixa próxima ao RSMV, como já foi dito, tem origem do aporte do principal tri- 
(A)

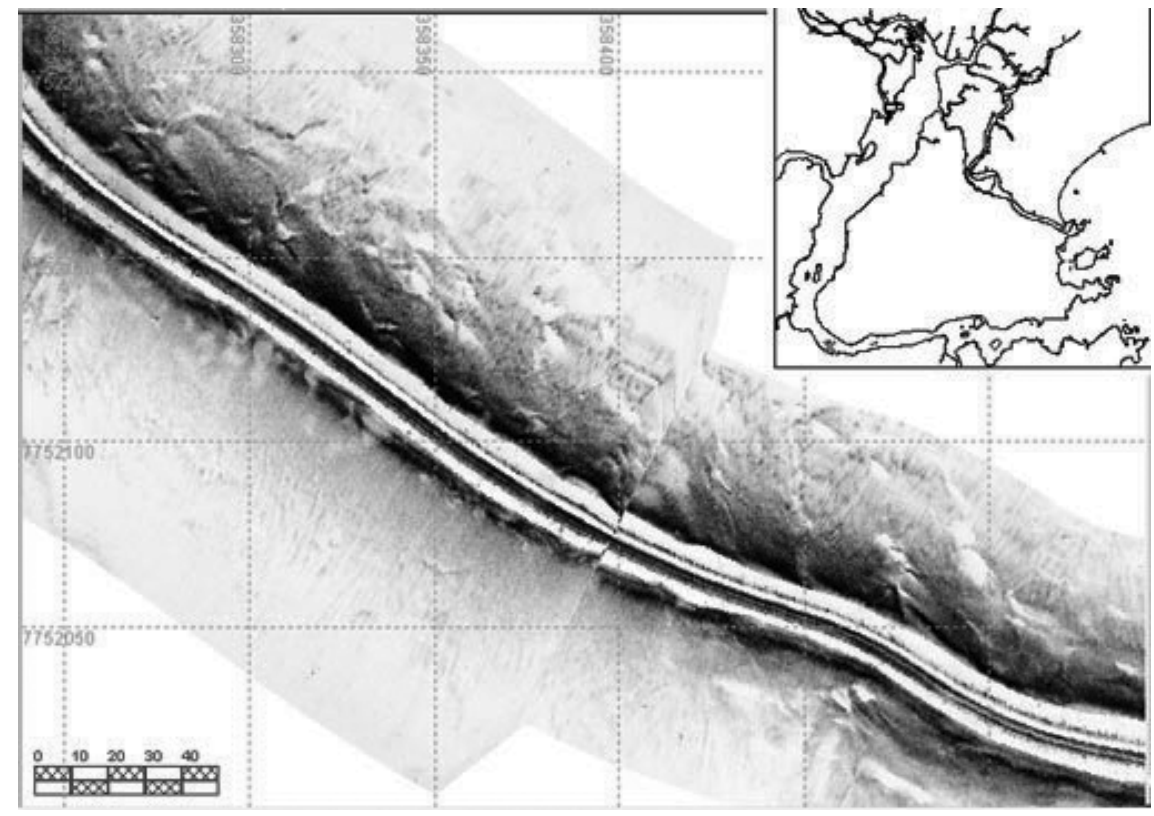

(B)

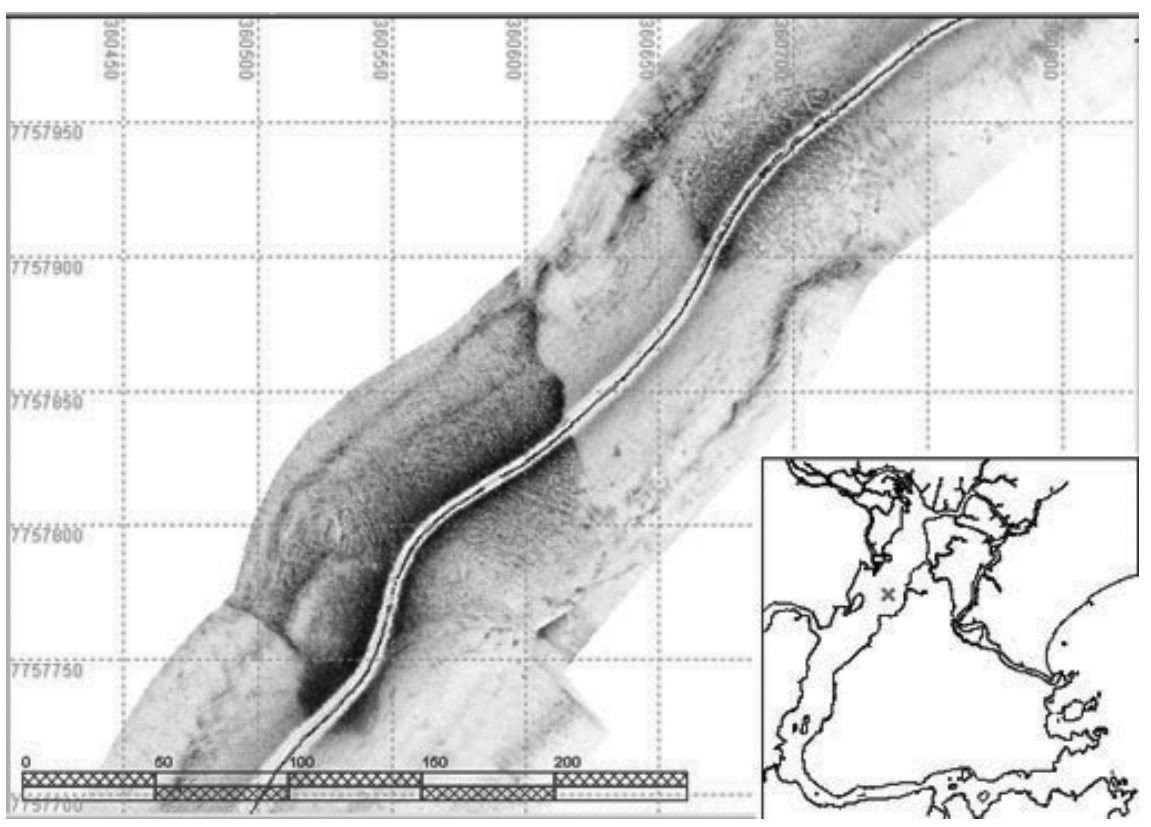

Figura 11 - Padrões associados a Formas de Fundo Irregulares. (A) Padrão de Formas de Fundo Irregulares ao sul do Rio Bubu, com baixa distinção do padrão de Fundo Homogêneo de Baixa Reflexão; (B) Padrão de Formas de Fundo Irregulares próximas ao RSMV, mostrando a diferenciação entre este ecocaráter e o predominante no estuário.

butário do sistema estuarino, caracterizando a frente deltáica. As outras duas faixas parecem ser resultantes do efeito de estrangulamentos da baía e pela presença dos maciços que formam 0 Arquipélago de Vitória, que aumentam as correntes neste trecho do ambiente em questão, ou seja, na inflexão da baía.

À medida que os sistemas fluviais perdem competência no transporte dos sedimentos, os sedimentos são gradualmente de- positados de acordo com seu diâmetro, ou seja, os sedimentos lamosos são os que alcançam maiores distâncias da foz dos rios, assim como descrito para deltas de cabeceira (Davis Jr, 1985). Esta gradação, típica de áreas de progradação de delta, é observada junto ao delta do RSMV nos mapas de classificação segundo Folk (1954) e no de teor de lama, porém não é tão evidente no mapa de classificação modificada de Larsonneur (Dias, 1996). 


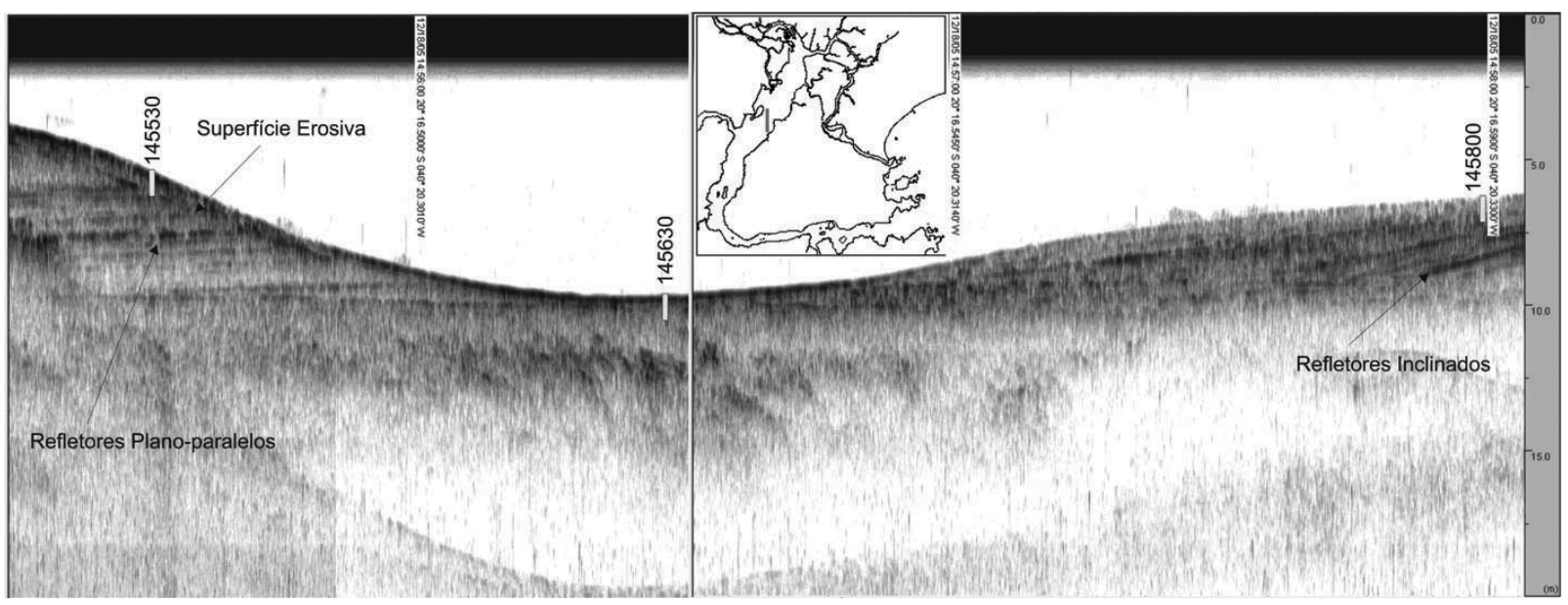

Figura 12 - Seção transversal ao canal principal com localização. Seção sísmica adquirida com perfilador de subfundo, modelo Stratabox-10 kHz.

Não foi possível explicar a ocorrência das Formas de Fundo Irregulares. Apesar desta realidade, estas formas de fundo parecem estar relacionadas à influência do teor de lama dos sedimentos destes trechos na formação das formas de fundo, já que estes apresentam concentrações de lama sempre entre 15 e 50\%. Esta concentração de lama estaria gerando coesão entre os grãos de areia e diminuindo o transporte por rolamento e saltação, dificultando assim 0 trabalho de transporte da fração arenosa dos sedimentos pelas correntes e a formação de Dunas Subaquosas.

Apesar disto, as Formas de Fundo Irregulares presentes junto ao delta do RSMV também foram relacionadas ao aporte sedimentar deste rio e as baixas correntes deste trecho, que não conseguem remobilizar todo 0 volume sedimentar que aporta a área formando Dunas Subaquosas.

A partir da Ilha das Caieiras em direção sul, o entorno da Baía sofre um estreitamento que provoca um alargamento e aprofundamento do canal principal. Esta mudança morfológica pode ter relação com 0 aumento da vazão encontrada nos poucos estudos já realizados na região (Chacaltana et al., 2003), que estaria associada a um aumento do fluxo sedimentar, removendo uma fração dos sedimentos finos deste trecho do sistema estuarino. Inclusive, como 0 ambiente em questão apresenta domínio das correntes de vazante (Rigo, 2004), os sedimentos remobilizados provavelmente estão sendo transportados em direção à desembocadura do estuário.

Ao longo de todo o trecho da baía com orientação NE-SW, que compreende da desembocadura do RSMV até a região de Santo Antônio, é observada a tendência de erosão do fundo, observada na seção sísmica apresentada por Bastos et al. (2007). As características erosivas observadas neste trecho podem estar indicando o retrabalhamento de sedimentos pretéritos que seriam parcialmente misturados com sedimento fino que aporta a região na atualidade. Isto indicaria que a maior parte dos sedimentos lamosos provenientes dos rios que aportam o estuário atualmente não permanece no fundo deste trecho do estuário, podendo estar sendo transportados para as planícies de manguezal e para áreas a jusante, como 0 Canal do Porto.

A faixa de margas presente no mapa de classificação segundo Dias (1996) está localizada junto ao canal central, e parece ser conseqüência da produção biológica local, apesar das descrições das amostras verificarem alto grau de fragmentação destes restos de organismos, o que sugere retrabalhamento. Esta alta concentração carbonática não é comum em estuários, o que indica que a mesma seja resultado do processo erosivo descrito, que estaria concentrando as frações de maior granulometria. Esta faixa pode estar sendo alterada pela pesca com redes de arrasto de fundo do tipo balão para pesca de camarão, exercida diariamente na região, que ressuspendem os sedimentos mais finos mecanicamente. Inclusive, a alta fragmentação dos sedimentos carbonáticos deste trecho do estuário estariam sendo provocadas por esta prática ilegal.

As imagens de sonar não apresentaram diferenças entre esta faixa de margas e os sedimentos predominantemente lamoarenosos do estuário, ambos sendo caracterizados pelo mesmo padrão predominante de Fundo Homogêneo. Este fato é provocado pelas características acústicas semelhantes destes sedimentos, fato incomum entre sedimentos de características granuIométricas e composicionais diferentes imageados sob a mesma condição ambiental. Porém, pode ser conseqüência da alteração diferencial de um mesmo depósito sedimentar.

0 padrão Dunas Subaquosas está associado à faixa arenolamosa delgada presente nos extremos da inflexão da Baía de 
Vitória, sendo também associado às margas e areias litoclásticas da classificação textural e composicional utilizada (Figs. 4, 5, 7 e 10). Estas Dunas Subaquosas parecem ser conseqüência dos estreitamentos naturais e artificiais da Baía de Vitória, que mantém este trecho do estuário com as correntes mais altas observadas na Baía de Vitória (Chacaltana et al., 2003; Rigo, 2004). Outra observação plausível é que as Dunas Subaquosas estão relacionadas ao segmento do perfil longitudinal de maior inclinação média, que corresponde à área que antecede a região dragada do estuário. A redução do nível de base relativo através da atividade de dragagem pode estar aumentando a tendência erosiva natural observada para a região do bairro Ilha das Caieiras até o final da inflexão da Baía de Vitória. Com isso, o processo de remoção da fração lamosa dos sedimentos pelas correntes pode ter se intensificado, permitindo que, com a diminuição da coesividade do fundo, a fração arenosa seja transportada pelo fundo, inclusive auxiliando a formação das Dunas Subaquosas e as Formas de Fundo Irregulares observadas neste trecho. 0 que corroboraria esta hipótese é 0 aumento da inclinação média do fundo observada no perfil longitudinal do estuário, justamente onde se restringem estas formas de fundo, ou seja, na região que antecede a área dragada.

Na região do Canal do Porto, os efeitos das intervenções realizadas até então são visíveis tanto na morfologia quanto na distribuição dos sedimentos. Na verdade, estes padrões não correspondem totalmente ao esperado por conseqüência das dragagens e aterros, que mascaram as características originais deste ambiente estuarino e determinam grande parte da morfologia e distribuição das propriedades granulométricas dos sedimentos. Isto é corroborado pela grande quantidade de marcas de dragagem e pela presença de pilares de pontes neste trecho da área de estudo. No entanto, a alta deposição de lama neste trecho do sistema estuarino rico em estreitamentos indica que as dragagens podem ter contribuído para redução da hidrodinâmica local, principalmente junto ao fundo, permitindo que ocorresse a deposição de sedimentos lamosos. Como as regiões a montante apresentam características que não favorecem a deposição sedimentar, com exceção da região do delta do RSMV, os sedimentos finos que aportam neste estuário provavelmente estão se depositando neste canal dragado, nas enseadas e áreas de planície de marés, quando estes permanecem no estuário.

Na desembocadura do sistema estuarino, apesar do imageamento novamente não mostrar diferenças entre as texturas sedimentares, ocorre o predomínio de areias retrabalhadas pela atuação de ondas na região.

Como esperado, o padrão de distribuição geral dos sedi- mentos, se analisados conjuntamente com os dados da Baía do Espírito Santo estudados por Albino et al. (2001) e Carmo (2006), apresenta sedimentos arenosos de origem marinha na região da desembocadura do estuário (Illha do Boi para a Baía do Espírito Santo), enquanto que a maior parte dos sedimentos analisados nestes trabalhos podem ser consideradas deposições lamosas centrais, com a presença das deposições fluviais junto ao RSMV e das áreas areno-lamosas associadas aos estreitamentos e a concentração dos sedimentos carbonáticos presentes na baía.

Este tipo de distribuição sedimentar, no geral, é comum em estuários devido à mistura de sedimentos fluviais e marinhos provocadas pelas ondas, marés e vazão dos rios. À medida que as forçantes adentram 0 ambiente estuarino estas perdem força, sendo que na região central, pela perda de energia das forçantes fluviais e marinhas, predomina a deposição de sedimentos lamoSoS (Davis Jr, 1985; Dalrymple et al., 1992; Perillo, 1996; Roy et al., 2001). Porém, as evidências de erosão do fundo encontradas na Baía de Vitória não eram esperadas com esta intensidade, apesar destas serem comuns em estuários onde ocorre e/ou ocorreu regressão marinha (Lessa et al., 1998, 2000; Lessa, 2005), já que os ambientes estuarinos são áreas de deposição sedimentar e progradação costeira. Como estes trabalhos são fundamentados em padrões evolutivos, a distribuição sedimentar observada na Baía de Vitória pode ser conseqüência de um padrão evolutivo diferente dos supostos nos trabalhos citados.

Para uma caracterização visual dos resultados deste trabalho, a Figura 13 ilustra as diferentes áreas do sistema estuarino e seus distintos processos predominantes.

\section{CONCLUSÃO}

No geral, o padrão de distribuição sedimentar existente na área de estudo se apresenta condizente com o padrão típico de ambientes estuarinos, apesar das particularidades apresentadas pelo sistema estuarino em questão, como a não-relação dos sedimentos com a hidrodinâmica atual deste ambiente e as evidências de erosão na região central do estuário presentes de forma tão pronunciada como a observada.

Os padrões de sonar, no geral, auxiliaram e facilitaram 0 entendimento desta distribuição, mostrando as feições de fundo de cada região e a complexidade do fundo do sistema estuarino.

De acordo com as características atuais, o sistema estuarino da Baía de Vitória parece estar sofrendo um processo de erosão provocada pela hidrodinâmica existente em seu canal central.

A distribuição dos teores de lama não apresentou a continuidade esperada para uma região central de um ambiente estuarino 


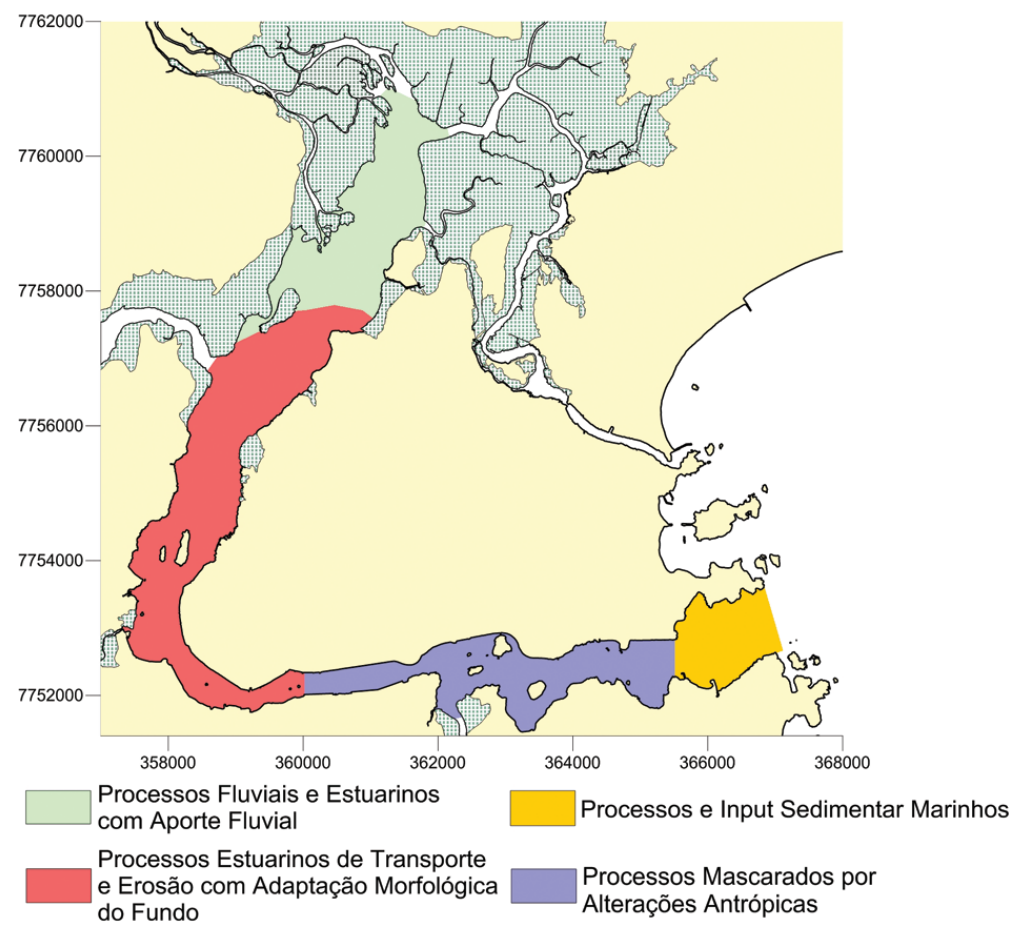

Figura 13 - Mapa geral dos processos sedimentares inferidos neste trabalho.

devido à existência dos estreitamentos do sistema, que enfatiza 0 domínio da morfologia na distribuição sedimentar deste ambiente, e da grande presença dos sedimentos carbonáticos.

Inclusive, a presença de carbonato e de afloramentos rochosos por grande parte da Baía de Vitória parecem ser as explicações para as pequenas manchas cascalhosas e arenosas encontradas ao longo de todo trecho central da área de estudo.

Os estreitamentos da Baía de Vitória parecem promover correntes intensas que controlam as formas de fundo destes trechos da baía, promovendo a formação das Dunas Subaquosas observadas.

Contudo, os fatores que parecem ser responsáveis pela manutenção e/ou intensificação das Dunas Subaquosas são os estreitamentos artificiais da baía e a redução de seu nível de base relativo através das dragagens, que provavelmente estão atuando de forma conjunta para a manutenção destas dunas, já que as hipóteses apresentadas não apresentam aspectos restritivos entre si.

0 Canal do Porto apresentou tanto a morfologia quanto as características sedimentares alteradas por intervenções antrópicas, como aterros, instalação de pilares de pontes e dragagens. Estas intervenções também parecem ser as responsáveis pela alta sedimentação desta região, provocada pelas dragagens que diminuíram a hidrodinâmica junto ao fundo deste trecho do estuário.

Todavia, são necessários mais estudos acerca da evolução e dinâmica sedimentar atual deste complexo sistema para que possam corroborar algumas das hipóteses apresentadas e aumentar 0 conhecimento sobre 0 ambiente marinho em geral e deste ambiente, especificamente.

\section{AGRADECIMENTOS}

Os autores gostariam de agradecer à Fundação de Amparo à Pesquisa do Espírito Santo (FAPES) pelo apoio financeiro (Projeto $31180787 / 05$ ) e pela bolsa de mestrado do primeiro autor (PVJ). Gostaríamos ainda de agradecer ao Núcleo de Competência em Óleos Pesados (COPES-PETROBRAS) pelo apoio financeiro e ao LABESUL, do Departamento de Engenharia Ambiental da UFES, em nome do Prof. Julio T.A. Chacaltana pela disponibilização dos dados batimétricos da porção superior da Baía de Vitória.

\section{REFERÊNCIAS}

ALBINO J, OLIVEIRA R, MAYA LP \& ALENCASTRE K. 2001. Processos Atuais de Sedimentação Marinha e Praial do Litoral de Vitória, ES. Relatório n. 1982506/2000. Prefeitura Municipal de Vitória, FACITEC: Vitória, Espírito Santo, 2001. 
ASHLEY GM. 1990. Classification of large-scale subaqueous bedforms: a new look at an old problem. Journal of Sedimentary Petrology, 60(1): 160-172.

AYRES NETO A. 2000. Uso da sísmica de reflexão de alta resolução e da sonografia na exploração mineral submarina. Revista Brasileira de Geofísica, 18(3): 241-256.

BASTOS AC, KENYON NH \& COLLINS M. 2002. Sedimentary processes, bedforms and facies associated with a coastal headland: Portland Bill, Southern UK. Marine Geology, 187: 235-258.

BASTOS AC, QUARESMA VS, DALMASCHIO RG, CARMO DA, SOUZA PM, LIMA B \& POZZI F. 2007. Dinâmica Sedimentar e Morfologia de Fundo do Sistema Estuarino de Vitória, ES. In: Congresso da Associação Brasileira de Estudos do Quaternário, 11., 2007, Belém. Anais... Belém: ABEQUA, 2007. CD-ROM.

BLOTT SJ \& PYE K. 2001. GRADISTAT: a grain size distribution and statistics package for the analysis of unconsolidated sediments. Earth Surface Processes and Landforms, 26(11): 1237-1248.

CAMARA G, SOUZA RCM, FREITAS UM \& GARRIDO J. 1996. SPRING: Integrating remote sensing and GIS by object-oriented data modelling. Computers \& Graphics, 20(3): 395-403.

CARMO DA. 2006. Aplicação do modelo de tendências granulométricas (GSTA) para determinação do padrão de transporte de sedimentos na Baía do Espírito Santo, Vitória - ES. Monografia, Programa de Graduação em Oceanografia, Universidade Federal do Espírito Santo, Vitória. 62 p.

CHACALTANA JTA, MARQUES AC, RIGO D \& PACHECO CG. 2003. Influência do manguezal no padrão de escoamento do sistema estuarino da Ilha de Vitória - ES. In: V Semana Estadual de Meio Ambiente (SESMA), Vitória, 2003. 1-7.

D’AGOSTINI DP. 2005. Fácies sedimentares associadas ao sistema estuarino da Baía de Vitória (ES). Monografia, Programa de Graduação em Oceanografia, Universidade Federal do Espírito Santo, Vitória. 63 p.

DALRYMPLE RW, ZAITLIN BA \& BOYD R. 1992. Estuarine Facies Models: conceptual basis and stratigraphic implications. Journal of Sedimentary Petrology, 62(6): 1130-1146.

DAVIS JR RA. 1985. Coastal Sedimentary Environments. SpringerVerlag, New York. $716 \mathrm{p}$.

DIAS GTM. 1996. Classificação de sedimentos marinhos: Proposta de Representação em Cartas Sedimentológicas. In: Congresso Brasileiro de Geologia, 39., 1996, Salvador. Anais... Salvador: SBG, 1996, 3: 423426.

DIAS JMA. 2004. A análise sedimentar e o conhecimento dos sistemas marinhos. Universidade do Algarve, Faro, Portugal, $84 \mathrm{p}$.

FOLK RL. 1954. The distinction between grain size and mineral composition in sedimentary-rock nomenclature. Journal of Geology, 62(4): 344-359.
FOLK RL \& WARD WC. 1957. Brazos River Bar: a study in the significance of grain size parameters. Journal of Sedimentary Research, 27(1): 3-26.

JESUS HC, COSTA EA, MENDONÇA ASF \& ZANDONADE E. 2004. Distribuição de metais pesados em sedimentos do sistema estuarino da Ilha de Vitória - ES. Química Nova, 27(3): 378-386.

LESSA GC. 2005. Baías Brasileiras: Grandes estuários em uma costa regressiva? In: X Congresso da Abequa, Anais..., Guarapari, ES. CD-ROM.

LESSA GC, MEYERS SR \& MARONE E. 1998. Holocene Stratigraphy in the Paranaguá Bay Estuary, Southern Brazil. Journal of Sedimentary Research, 68(6): 1060-1076.

LESSA GC, BITTENCOURT ACSP, BRICHTA A \& DOMINGUEZ JML. 2000. A Reevaluation of the Late Quaternary sedimentation in Todos oS Santos Bay (BA), Brazil. Anais da Academia Brasileira de Ciências, 72(4): 573-590.

LIMA JR CB, SOARES SC \& BONICENHA W. 1994. Baía de Vitória: aspectos históricos e culturais. Fundação Ceciliano Abel de Almeida, Vitória. $119 p$.

MACIEL MA, CHACALTANA JTA \& RIGO D. 2003. Padrão de escoamento no Canal da Passagem. In: V Semana Estadual de Meio Ambiente (SESMA) Vitória, 2003.

MIRANDA LB, CASTRO BM \& KJERFVE B. 2002. Princípios de oceanografia física de estuários. EDUSP, São Paulo. 417 p.

NUNES AL. 2005. Modelo histórico das alterações fisiográficas recentes da Baía de Vitória (ES) e áreas adjacentes, com 0 uso de sistema de informações geográficas. Monografia de Graduação, Programa de Graduação em Oceanografia, Universidade Federal do Espírito Santo, Vitória. 80 p.

PAOLO FS \& MAHIQUES MM. 2008. Utilização de métodos acústicos em estudos de dinâmica costeira: exemplo na desembocadura lagunar de Cananéia. Revista Brasileira de Geofísica, 26(2): 211-225.

PERILLO GME. 1996. Geomorphology and sedimentology of estuaries. Elsevier, Amsterdam. $471 \mathrm{p}$.

Projeto RADAMBRASIL. 1983. Levantamento de Recursos Naturais, Vol. 32. Folha SF.23/24 Rio de Janeiro/Vitória. Escala 1:1.000.000. Ministério de Minas e Energia, Rio de Janeiro, 1983.

QUARESMA VS, DIAS GTM \& BAPTISTA NETO JA. 2000. Caracterização da ocorrência de padrões de sonar de varredura lateral e sísmica de alta frequência (3,5 e 7,0 kHz) na porção sul da Baía de Guanabara - RJ. Revista Brasileira de Geofísica, 18(2): 201-214.

RIG0 D. 2004. Análise do escoamento em regiões estuarinas com manguezais - medições e modelagem na Baía de Vitória, ES. Tese de Doutorado, Programa de Pós-Graduação em Engenharia Oceânica, COPPE, UFRJ, Rio de Janeiro. 156 p. 
ROY PS, WILLIAMS RJ, JONES AR, YASSINI I, GIBBS PJ, COATES B, WEST RJ, SCANES PR, HUDSON JP \& NICHOL S. 2001. Structure and Function of South-east Australian Estuaries. Estuarine, Coastal and Shelf Science, 53: 351-384.
SARMENTO R. 1993. Determinação do Tombo da Maré no Canal da Passagem. Relatório Final, Laboratório de Hidráulica, Universidade Federal do Espírito Santo, Vitória. 33 p.

\section{NOTAS SOBRE OS AUTORES}

Paulo Veronez Júnior. Graduado em Oceanografia pela UFES (2005), mestre em Oceanografia Ambiental pela UFES (2009), atua na área de geofísica marinha e dinâmica sedimentar.

Alex Cardoso Bastos. Geólogo graduado pela UFRJ (1994), mestre em Geologia e Geofísica Marinha pelo Laboratório de Geologia Marinha da UFF (1997), doutor em Oceanografia Geológica pela University of Southampton (2002), Pós-doutorado em Sísmica de Alta Resolução pelo National Oceanography Centre-UK (2004), desde 2004 é professor adjunto da UFES e desde 2009 é pesquisador nível II do CNPq.

Valéria da Silva Quaresma. Geógrafa graduada pela UFF (1992), mestre em Geologia e Geofísica Marinha pelo Laboratório de Geologia Marinha da UFF (1997), doutora em Oceanografia Geológica pela University of Southampton (2004), desde 2006 é professora adjunta da UFES atuando na área de dinâmica sedimentar e geofísica de alta resolução aplicada. 